\title{
Metástasis pulmonar de tumor de células de la granulosa como recurrencia del tumor primario después de diez años del tratamiento quirúrgico
}

\author{
Miguel Cerón Terán ${ }^{1}$, Edgardo Mancilla Sierpe. ${ }^{1}$ \\ ${ }^{1}$ Unidad de Anatomía Patológica, Hospital Regional de Antofagasta. Chile.
}

\section{RESUMEN}

Los tumores de células de la granulosa son neoplasias de bajo grado, que corresponden al $2-5 \%$ de los tumores malignos del ovario y presentan una baja incidencia. Las manifestaciones clínicas dependerán del tamaño tumoral y de la exposición prolongada a estrógenos producidos por las células neoplásicas. Habitualmente, son tumores unilaterales, sólido-quísticos con focos de hemorragia, constituidos por células pálidas con su característico pliegue nuclear, en un trasfondo fibrotecomatoso, con cuerpos de Call Exner sólo en el 30-60\% de los casos. El diagnóstico se realiza con los niveles séricos de estradiol y con exámenes imagenológicos como ecotomografía ginecológica, tomografía axial computarizada o resonancia nuclear magnética. El tratamiento quirúrgico es la elección. Las recurrencias pueden ocurrir años posteriores al diagnóstico inicial y en general son pélvicas. El factor pronóstico más determinante en la evolución de la enfermedad es el estadio clínico al momento del diagnóstico. Se presenta el caso clínico de una paciente postmenopáusica con metástasis pulmonar de tumor de células de la granulosa después de diez años del tratamiento quirúrgico.

\section{PALABRAS CLAVES: Tumor de células de la granulosa, metástasis pulmonar}

\section{SUMMARY}

The granulosa cell tumors are low grade neoplasias that correspond to $2-5 \%$ of all malignant tumors of the ovary with a low incidence in the population. The clinical presentation depends on the tumor size and the long term exposition to estrogens produced by neoplastic cells. They are usually unilateral tumors exhibiting a mixture of cystic and solid areas with bleeding, constituted by pale cells with their characteristic nuclear groove in a fibrotecomatous background, with Call Exner bodies only in 30-60\% of cases. The diagnosis is done with serum levels of estradiol and gynecological imaging analysis such as echotomography, Computerized axial tomography and magnetic nuclear resonance. The surgical treatment is the choice. The recurrences could happen years after the first diagnosis and usually are in pelvic area. The most important prognostic factor in the disease progression is the clinical stage at diagnosis. It is presented a case report of a postmenopausal patient with lung metastasis of granulosa cell tumor after ten years of surgical treatment.

KEY WORDS: Granulosa cell tumor, lung metastasis 


\section{INTRODUCCIÓN}

Los tumores de células de la granulosa son neoplasia de bajo grado constituidas puramente de células de la granulosa o al menos en un 10\% del tumor, con un trasfondo fibrotecomatoso y que corresponden al $70 \%$ de los tumores de cordones sexuales/estroma (1). En general, se presentan en la edad adulta con una media de 50 a 54 años, pero el $5 \%$ ocurre antes de la pubertad $(2,3,4)$. Su etiología es aún incierta y el tratamiento quirúrgico escogido dependerá de la edad de la paciente, pudiendo corresponder sólo a la anexectomía o la histerectomía más salpingooforectomía bilateral $(1,2)$. En general, tienen un buen pronóstico que depende del estadio clínico al momento del diagnóstico. Las recurrencias y metástasis son raras y generalmente ocurren en la zona pélvica $(3,5,6)$.

Se reporta el caso de una mujer postmenopáusica que posterior a 10 años de una ooforectomía izquierda por un tumor de células de granulosa exhibe metástasis retroperitoneales y pulmonares.

\section{Caso clínico}

Paciente de sexo femenino de 66 años con antecedentes de hipertensión arterial, hipotiroidismo e historia de tumor ovárico izquierdo operado en 1991, cuyo exámen histopatológico informó un tumor de células de la granulosa que pesó 1.300 gramos y midió $28 \mathrm{~cm}$ en su diámetro mayor. Mostraba un patrón de crecimiento difuso y en partes trabecular y microfolicular, infiltrando totalmente la pared del ovario sin comprometer la serosa. En el año 2008 tras la realización de una tomografía axial computada (TAC) de abdomen y pelvis se halló un tumor renal izquierdo con localizaciones secundarias ganglionares hiliares y diseminación pulmonar al lóbulo inferior izquierdo. Se efectúa nefrectomía total izquierda cuyo estudio histopatológico muestra un carcinoma renal de células claras Fuhrman 2, con compromiso focal de la cápsula. En esa intervención paralelamente se realiza la extirpación de una masa pre-aórtica que corresponde a una lesión sólido-quística con atipias leves, núcleos en grano de café y escaso citoplasma con receptores de estrógeno, progesterona e inhibina positivas. Por lo cual, se diagnostica metástasis retroperitoneal de tumor de células de la granulosa.

Se realizó seguimiento de los nódulos pulmonares pesquisados en el lóbulo inferior del pulmón izquierdo observándose un crecimiento lento desde $9 \mathrm{~mm}$ a $18 \mathrm{~mm}$ en uno de ellos y de $2,5 \mathrm{~mm}$ a 32 $\mathrm{mm}$ en el otro (Figuras 1 y 2). Se decide entonces realizar punción de aquéllos, que fueron reportados como fragmentos de tumor maligno mesenquimal constituido por células ovoideas de núcleos en granos de café, algunos con nucléolo prominente y escaso citoplasma, dispuestas en un patrón trabecular y en parte microfolicular, sin focos de necrosis, hemorragia ni mitosis (Figuras 3 y 4). El estudio inmunohistoquímico con anticuerpos monoclonales contra Inhibina a y CD99 fue positivo intenso (Figuras 5 y 6) y negativo para pancitoqueratinas (AE1/ AE3), EMA, TTF-1, Cromogranina-A, Sinaptofisina, CD45 y CD56. En base a estos hallazgos se diagnostica metástasis pulmonar de tumor de células de granulosa.

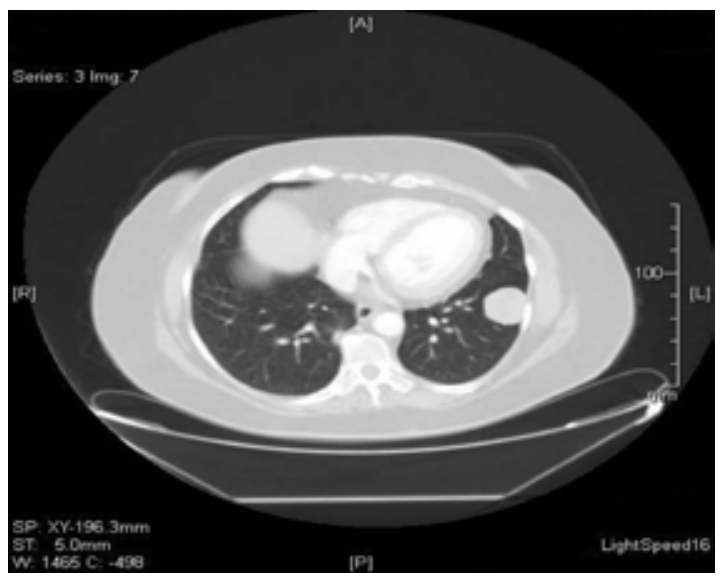

Figura 1. TAC de tórax con ventana pulmonar. Se observa nódulo en segmento anterolateral del lóbulo izquierdo bien definido, redondeado de $33 \mathrm{~mm}$.

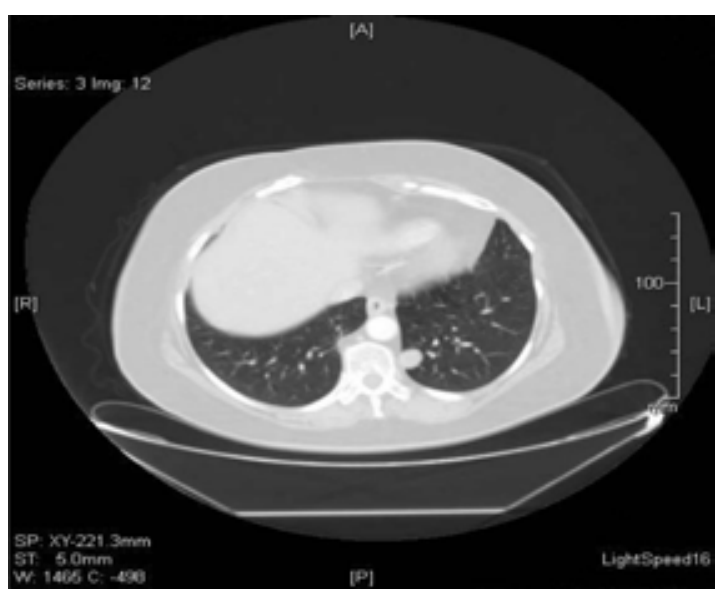

Figura 2. TAC de tórax con ventana pulmonar. Se observa nódulo en segmento basal medial del lóbulo izquierdo bien definido, redondeado de $18 \mathrm{~mm}$. 


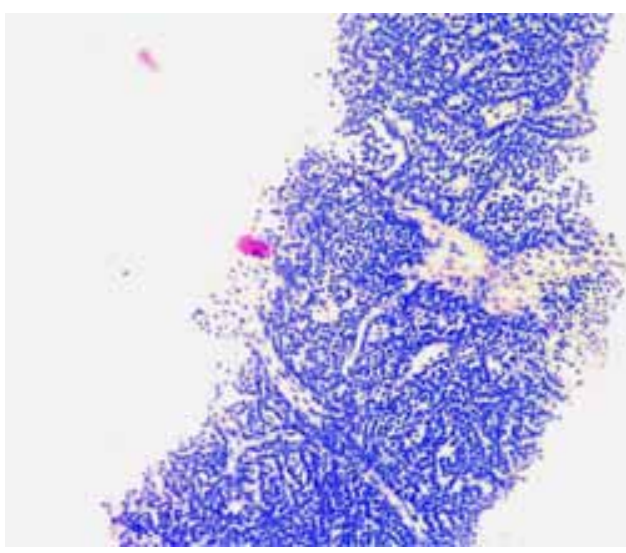

Figura 3. Microfotografía en la que se observa el patrón trabecular y microfolicular del tumor (Tinción HE, 4x).

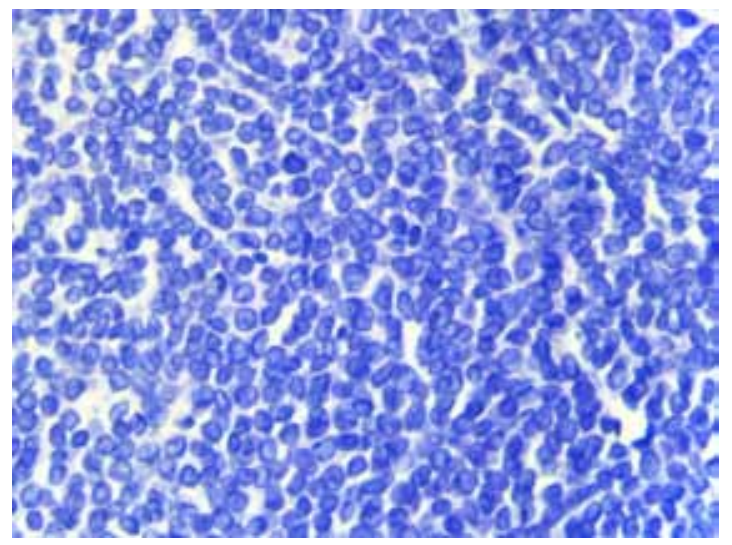

Figura 4. Microfotografía en la que se observa el detalle celular. Es posible ver numerosos núcleos con la típica descripción "en grano de café" (Tinción HE, 20x).

Se realiza el seguimiento de la paciente en el policlínico de oncología del Hospital Regional de Antofagasta y se propone realizar radioterapia estereotáxica curativa, la cual completó sin incidentes, debido a que la paciente rechazó la metastasectomía.

\section{DISCUSIÓN}

Según la Organización Mundial de la Salud, los tumores de células de la granulosa son neoplasias constituidas puramente de células de la granulosa, o al menos en un $10 \%$ del tumor, con un trasfondo

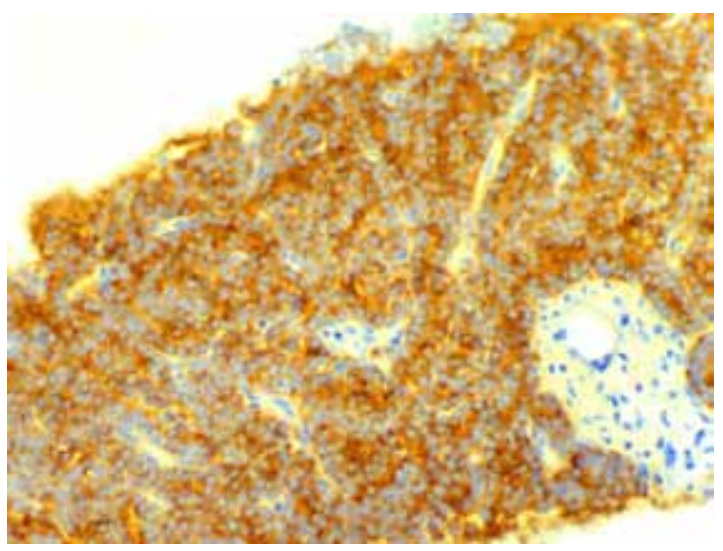

Figura 5. Tinción inmunohistoquímica con anticuerpos contra Inhibina a (20x).

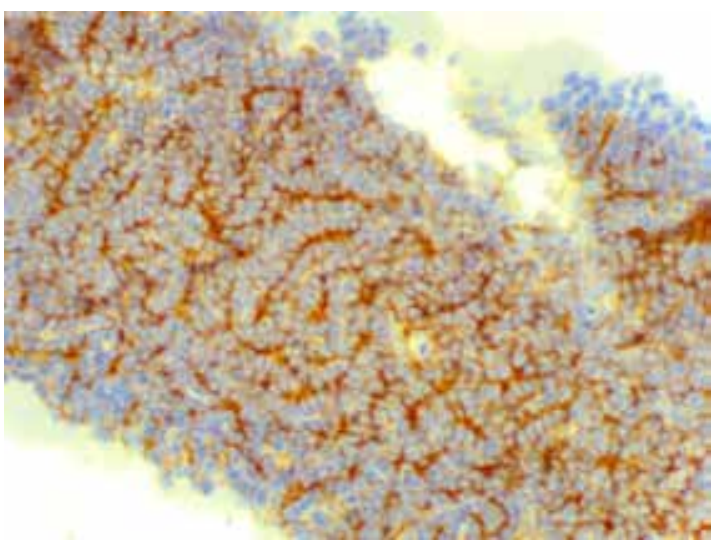

Figura 6. Tinción inmunohistoquímica con anticuerpos contra CD99 (20x).

fibrotecomatoso (1). Corresponden a tumores de bajo grado del ovario y que representan aproximadamente el $2-5 \%$ de los tumores malignos ováricos y el $70 \%$ de los tumores de cordones sexuales/estroma. Se estima una incidencia de 0,99/100.000 habitantes en EE.UU. En general, son unilaterales pero existen casos bilaterales (3\%). La edad promedio de presentación es 50 a 54 años, pero el $5 \%$ ocurre antes de la pubertad y el $60 \%$ en la postmenopausia $(1,4)$. Su etiología es desconocida pero se han hallado algunos factores de riesgo como la infertilidad y la exposición a agentes inductores de la ovulación. 
Los tumores de células de la granulosa se dividen en dos tipos: el tipo adulto que presenta al 95\% de estos tumores y el resto correspondiente a los tumores de células de la granulosa juvenil $(1,2,7)$.

Pueden ser productores de estrógenos o andrógenos por la presencia de las células de la teca que liberan androstenediona pasando a las células de la granulosa que la transforman en estradiol $(2,5)$. De esta manera los síntomas con los que habitualmente debutan las pacientes son menometrorragia, dada la exposición prolongada a estrógenos, o amenorrea secundaria. Es raro que produzcan infertilidad. En niñas puede generar pubertad precoz (8). El dolor puede ocurrir con o sin masa palpable pero generalmente ocurre cuando el tumor alcanza un tamaño superior a 10-15 cm, en la torsión ovárica, en los casos con hemorragia intratumoral o la rotura.

El diagnóstico preoperatorio es habitualmente a través de una ecotomografía ginecológica y los niveles de estradiol. Sin embargo, la TAC y la resonancia nuclear magnética (RNM) juegan un rol importante en la planificación quirúrgica para evaluar la resecabilidad del tumor. Al momento del diagnóstico el tumor alcanza en promedio un tamaño de $12 \mathrm{~cm}$ y macroscópicamente presenta un componente sólido necrótico y/o quístico de contenido serosanguinolento o gelatinoso (3).

Histológicamente, corresponde a células de la granulosa pequeñas, pálidas, redondas u ovales con núcleos en grano de café. Los cuerpos de Call Exner, característicos de la forma adulta, se presentan en el 30-60\% de los casos. Existen distintos patrones arquitecturales: insular, microfolicular, macrofolicular, trabecular, difuso o una combinación de estos. Raramente se encuentra un índice mitótico que exceda 1-2 mitosis en 10 campos de aumento mayor. Cuando el tumor está luteinizado las células exhiben un citoplasma eosinófilo abundante, vacuolado y el núcleo se hace redondo perdiendo el característico pliegue. Los principales marcadores inmunohistoquímicos expresados por el tumor son Vimentina, CD99 y alfa inhibina $(1,2,7)$.

El diagnóstico diferencial se plantea entre carcinomas indiferenciados, adenocarcinomas poco diferenciados, tumores carcinoides, carcinoma endometrioide, sarcoma estromal, metástasis de melanoma y de mama $(1,2,3,7)$.

Respecto del tratamiento, la histerectomía total más anexectomía y omentectomía es la elección en mujeres postmenopausicas. Sin embargo, en mujeres premenopáusicas el tratamiento es más conservador considerándose la anexectomía unilateral y legrado endometrial para descartar el carcinoma endometrial. Una vez removido el tumor los signos de hiperestrogenismo regresan y el sangrado cede en uno a dos días en mujeres jóvenes que han conservado el útero. En los casos de estadio avanzados (II a IV), recurrencia y/o metástasis está indicada la quimioterapia en distintos esquemas. La radioterapia y la hormoterapia es discutida $(2,3,4,5)$.

Normalmente, el diagnóstico es en estadio I (85-90\%) y presentan un crecimiento lento con una diseminación local y recurrencia tardía (10 a 50\%) y pueden manifestarse incluso 20 a 30 años posteriores al diagnóstico inicial. Las metástasis son raras y pueden ocurrir muchos años después, como en este caso, y ocurren a pulmón, hígado (5-6\% de todas las recurrencias) y hueso $(1,2,4,5,6)$. El seguimiento con $\mathrm{Ca}-125$ y alfa inhibina sérica permitirán la identificación precoz de las recidivas y la respuesta a terapia en un $100 \%$ pero no mejorarían la sobrevida $(3,5)$.

El factor pronóstico más importante es el estadio del tumor al momento del diagnóstico. Sin embargo, no existe consenso en el real significado que pudieran tener otros factores, como la edad mayor de 40 años, la bilateralidad, el tamaño tumoral mayor de $15 \mathrm{~cm}$, el índice mitótico y las atipias nucleares $(1,2,7)$.

\section{CONCLUSIÓN}

Los tumores de células de la granulosa son tumores de bajo potencial maligno y baja incidencia que generalmente se manifiestan por síntomas de hiperestrogenismo y con menor frecuencia, por masa palpable y dolor abdominal. Si bien, se presentan predominantemente en mujeres postmenopáusicas también pueden aparecer en mujeres jóvenes. El tratamiento quirúrgico es la elección terapéutica en estadio tempranos y el carácter conservador dependerá de la edad de la paciente. Sin embargo, en estadio avanzados la quimioterapia es la indicada.

\section{REFERENCIAS}

1. Tavasolli F, Mooney E, Gersell D, McCluggage W, et al. Sex cord-stromal tumors. In Fattaneh A. Tavassoli and Peter Devilee (Eds). Pathology and genetics of tumors of breast and female genital organ. Lyon: International Agency for Research on Cancer, 2003; 146-149.

2. González-Díaz E, Fernández C, Salas J, González C. Tumor de células de la granulosa tipo adulto de ovario. Prog Obstet Ginecol 2008;51(10):593-604.

3. Ortega A, Pérez M, Martínez M, Serrano J, Cantú D. Recurrencia tardía del tumor de células de la granulosa: presentación de un caso. Gaceta Médica de México 2012;148:302-6.

4. Ellouze S, Krichen-Makni S, Trabelsi K, Ayadi L, Sellami A, Khabir A, et al. Tumeur de la granulosa de l'ovaire. Á propos de 16 cas. J Gynecol Obstet Biol Reprod 2006;35(1):767-72. 
5. López C, Mardones R, Mucientes F, Klaassen R, Röessle A, Alarcón E. Tumor de células de la granulosa ovárico con metástasis pulmonares 26 años después. Rev Chil Obstet Ginecol 2009;74(5):307-10.

6. Yu S, Zhou X, Hou B, Tang B, Hu J, He S. Metastasis of the liver with a granulosa cell tumor of the ovary: A case report. Oncology Letters 2015; 9:816-8.
7. Young R. Sex cord-stromal, steroid cell and other ovarian tumors with endocrine, paraendocrine, and paraneoplastic manifestations. In: Kurman R, Hedrick L, Ronnett B (Eds). Blaustein's pathology of female genital tract (6th Edition). New York: Springer, 2011:785846. 